\section{La posmodernidad, su comprensión filosófica, económica Y social en el siglo XXI}

Postmodernism, its philosophical, economic and social understanding in the XXI Century

\section{Jorge Alirio Ochoa Lancheros*}

Recibido: 28-08-2014 / Revisado: 29-09-2014 / Aceptado: 09-04-2015

\section{Resumen}

La descripción sobre la filosofía positivista y el desarrollo de las metáforas sobre las teorías filosóficas, con base en las concepciones de la modernidad y posmodernidad (no confundir con modernismo y posmodernismo), han sido analizadas y expuestas en la tesis de Fritjof Capra, la cual corresponde, como científica, a la complejidad de la filosofía de la posmodernidad. Luego, en su obra The Hidden Connections: A Science for Sustainable Living (2003), aparece su posición crítica y contributiva en el espectro de la nueva conceptualización y comprensión del componente

\footnotetext{
1 Artículo de reflexión, resultado de la línea temática de investigación: Administración y Gestión de Negocios Internacionales.

* Economista, Universidad Pedagógica y Tecnológica de Colombia. Especialista en Gerencia Hospitalaria, Escuela Superior de Administración Pública. Especialista en Ciencia Política, Universidad de Boyacá. Especialista en Pedagogía para el Desarrollo del Aprendizaje Autónomo y Significativo, Universidad Nacional. Magíster en Desarrollo Rural, Pontificia Universidad Javeriana y PhD en Administración de Empresas, Atlantic International University of United States. Docente Universidad de Boyacá, docente investigador Universidad Santo Tomas, docente Fundación Universitaria Juan de Castellanos. Catedrático de las universidades ESAP, UPTC y Antonio Nariño. jorgeochoalancheros@gmail.com
}

de las redes sociales en el contexto de la posmodernidad. A través de la observación y la lectura de esta posición crítica, se puede entender el posmodernismo filosófico y la economía social de este siglo.

Palabras clave: biología, filosofía, física cuántica, globalización, modernidad, modernismo, sociología, posmodernidad, posmodernismo, química, sistema económico, sistema político y transculturización. 
Ochoa, J. (2015). La posmodernidad, su comprensión filosófica, económica y social en el siglo XXI.

Visión Empresarial, 1 (1). 102-121.

\begin{abstract}
The description on positivist philosophy and the development of metaphors about philosophical theories, based on the concepts of modernity and postmodernity (not to be confused with modernism and postmodernism) have been analyzed and exposed in the thesis by Fritjof Capra, which corresponds, as scientist, to the complexity of the philosophy of postmodernism. Later in his book The Hidden Connections: a Science for Sustainable Living (2003), appears his critical position and contribution in the field of the new conceptualization and understanding of the component of social networks in the context of postmodernism. Through observation and reading of this critical position, one can understand the philosophical postmodernism and social economy of this century.
\end{abstract}

Keywords: biology, philosophy, quantum physics, globalization, modernity, modernism, sociology, postmodernity, postmodernism, chemistry, economic system, political system and acculturation.

\section{Introducción}

La línea divisoria del conocimiento se ha dado a través de las lecturas de la filosofía positivista (leyes), la cual surge en Francia a inicios del siglo XIX, expresada por sus máximos exponentes en su parafernalia o epistemología, tales como Claude-Henri de Rouvroy Saint Simón, quien, gracias a sus estudios científicos sobre la sociedad, la política y la moral, es considerado como el fundador del socialismo; e Isidore Marie François Xavier Auguste Comte, quien fue reconocido como el padre de la sociología. John Stuart Mill, filósofo y economista británico, fue uno de los pioneros en la defensa de los derechos de las mujeres, reconocido como 
el defensor del género, frente al pensamiento contemporáneo. Ellos son considerados genéricamente como la modernidad y la posmodernidad; luego estos paradigmas antiguos y nuevos en forma análoga y concreta son metáforas producidas por la investigación y el desarrollo del ser humano en la búsqueda insaciable de la verdad (Mill, 1865).

En cuanto a lo contemporáneo, encontramos las siguientes categorías, a saber: el Círculo de Viena, la fenomenología social, las filosofías de los siglos XX y XXI, tales como el posestructuralismo y la posmodernidad.

Los estudios de Ludwig Josef Johann Wittgenstein, filósofo, matemático, lingüista y lógico austriaco, quien elabora el texto de inspiración del Círculo de Viena, y del británico Bertrand Arthur William Russell, filósofo, matemático, lógico y escritor, ganador del Premio Nobel de Literatura, tienen como objeto social alejar la ciencia de la metafísica, a partir del desarrollo de la lógica de Russell.

En cuanto a la fenomenología social, encontramos a Edmund Gustav Albrecht Husserl, nacido en Moravia hoy República Checa, filósofo creador de la fenomenología transcendental. Desde luego, a través de sus estudios deja para el siglo XX la concepción filosófica del movimiento de la fenomenología y para el siglo XXI aún llega este movimiento con vitalidad y vigencia para la investigación científica (Husserl, 1900).
Jean-Luc Marion es uno de los filósofos franceses de más renombre en el mundo y dentro de los que se encuentran vivos, su característica principal es el pensamiento sobre la fenomenología con base en la filosofía del amor, la intencionalidad y el orden del don de gentes, su género de investigación científica corresponde a la fenomenología, la desconstrucción y la posmodernidad por su ubicación en el espacio y tiempo, pero su línea sobresaliente de investigación corresponde a la fenomenología social.

El término posestructuralismo es polémico porque corresponde a la filosofía desarrollada por algunos filósofos que pertenecieron a la escuela estructuralista, tales como: Jacques Lacan, quien incorporó a su vez elementos del estructuralismo (y por sus investigaciones es considerado como el autor del renacimiento de Sigmund Freud, además era un médico psiquiatra y psicoanalista), Michel Foucault, Roland Barthes y Claude Lévi-Strauss, entre otros. En forma más precisa quienes se han destacado como fundamentalistas dentro del posestructuralismo aparecen: Jacques Derrida, Gilles Deleuze y Julia Kristeva, los cuales son considerados como filósofos prominentes del posestructuralismo (Lacan, 1971).

Jacques Derrida (1930-2004), filósofo francés, sus aportes científicos han sido reconocidos dentro del pensamiento de la desconstrucción y por ello se ha ganado el nombre del nuevo Immanuel Kant, pronunciado por 
Emmanuel Lévinas y por parte de Richard Rorty, considerado como el nuevo Friedrich Nietzsche.

Gilles Deleuze (1925-1995), filósofo de nacionalidad francesa, considerado por sus investigaciones sobre la historia de la filosofía, la política, la literatura, la pintura y el cine, como uno de los filósofos más sobresaliente en el siglo XX; se destacó por sus investigaciones en la ciencia política hasta el punto de ser considerado como un filósofo anarquista, porque siempre se apoyaba en Marx para abordar la filosofía política desde la teoría de las relaciones sociales del capitalismo. También es considerado y destacado dentro del pensamiento de las corrientes postmodernas (Deleuze, 2001)

Julia Kristeva (1941), psicoanalista, escritora, feminista, literata y filósofa francesa; en la actualidad es docente de semiología en la State University de New York; su investigación se basa en la crítica al estructuralismo. Ha sido criticada fuertemente por Alan David Sokal, científico norteamericano (quien se define como una persona de ideas políticas de izquierda posmoderna) y Jean Bricmont a través de su libro Imposturas Intelectuales, en el cual afirman que los escritos de Kristeva son para impresionar a un lector desprevenido en estos ejes temáticos y además que no son coherentes y congruentes por falta de justificación teórica (Sokal \& Bricmont, 1999).
Por último, la cultura o filosofía de la posmodernidad hace referencia a la socialización y civilización de las nuevas culturas, por ejemplo, en el ámbito de la filosofía política a través de los sistemas políticos contemporáneos, al igual que con las características sociales y económicas, como estadios sociales y sistemas económicos respectivamente, para lo cual aparecen innovaciones tecnológicas como las TIC y la globalización de la economía.

Por tal razón, la posmodernidad se plantea dentro de un contexto globalizado y multicultural, y su desarrollo se observa en el multiculturalismo y en los movimientos feministas con expresión de diferencia (visibilidad). También el término posmodernidad ha dado paso a otros pensamientos o filosofías tales como modernidad tardía, sociedad de riesgo y globalización. Por ello aparece como crítico de la corriente de la posmodernidad Jürgen Habermas, filósofo y sociólogo alemán, quien afirma que "más que buscar una postmodernidad, hay que llevar a cabo <como proyecto filosófico y político> una nueva ilustración de la modernidad" (Habermas, 1998). Desde luego que en el desarrollo de la ciencia política es imprescindible ir a la par con el desarrollo de la ciencia económica.

El filósofo italiano Gianni Vattimo (2007) defiende el pensamiento posmoderno con claridad cuando considera que: "lo importante no son los hechos sino sus interpretaciones. Así como el tiempo depende de 
la posición relativa del observador, la certeza de un hecho no es más que eso, una verdad relativamente interpretada y por lo mismo, incierta".

La posmodernidad se convierte en la vida del desencanto, se aparta de las utopías y de las ideas del progreso en conjunto; se apuesta a la carrera del progreso individual, bajo la representación de la filosofía de la competencia en las universidades y laboralmente en las empresas, con beneficio de inventario en la extracción intelectual del ser humano. Aparecen cambios en el orden económico capitalista, pasando de una economía de producción a una economía del consumo. La defensa del medio ambiente y la revalorización por la explotación económica de la naturaleza, se mezclan con la imposición al consumo, a través de los medios, los cuales anuncian según los tentáculos de sus intereses. Los medios masivos y la industria del consumo masivo se convierten en centros de poder, aparece la elección de los líderes a través de la imagen y desaparece la ideología como forma de elección de los mismos. Los medios masivos se erigen en portadores de la "verdad"; luego, lo que no aparece en los medios, simplemente no existe para la sociedad, y en el contexto de las redes sociales se pierde la intimidad y la vida se convierte en un show.

\section{El componente de las redes sociales en el contexto de la posmodernidad}

Fritjof Capra, de nacionalidad austriaca, doctor en física teórica (cuántica), ha estudiado rigurosa y profundamente las consecuencias filosóficas en las ciencias naturales y sociales, con el objeto social de ser replanteadas en la posmodernidad.

A través de la lectura, el análisis y la comprensión de su tesis argumentativa sobre el componente de las redes sociales, en su obra The Hidden Connections: $A$ Science for Sustainable Living (2003) (Las conexiones ocultas: una ciencia para la vida sostenible), aparecen planteamientos sobre los componentes de los métodos de investigación científica en las áreas de las ciencias naturales y las ciencias sociales. Menciona los instrumentos de investigación cuantitativa e investigación cualitativa y, en particular, plantea que los métodos utilizados como lo lineal no han dado resultados positivos en los aspectos sociales, mientras que en los planteamientos no lineales (cualitativos), se pueden observar resultados que en un momento dado se han considerado intangibles, como en el caso del daño al planeta ocasionado por la política económica neoliberal.

Para poder abordar la temática sobre el componente de las redes sociales, es necesario ordenar los contenidos de la obra de Capra, además es imperioso por su 
disciplina como investigador en la ciencia de la microbiología. La primera parte de la obra en mención (2003), titulada La vida, la mente y la sociedad, hace referencia a las teorías del origen de la evolución o desarrollo de la vida del hombre, a partir de la obra de Charles Darwin sobre la composición de la célula, como organismo de vida, argumento que establece en su obra El origen de las especies por medio de la selección natural (1859). Desde luego que tuvo en cuenta un corte cronológico sobre los estudios de la célula desde hace más de tres mil millones de años aproximadamente, y abordados por diferentes científicos, en cuanto la mente lo plantea a través de lo cognitivo y lo enlaza con respecto a la organización social.

En la segunda parte del libro, titulada Los retos del siglo XXI, Capra (2003) hace un profundo análisis con base en las redes sociales, el capitalismo global, y la vida y liderazgo en las organizaciones. Nos detendremos en dicho capítulo porque contiene el componente social de nuestros días, y su análisis se resaltará más adelante.

También es importante para Capra la reflexión sobre la naturaleza de la vida y en especial sobre las características definitorias de la realidad social, para extenderse luego a la realidad biológica, con conceptos correspondientes a las ciencias naturales.
En palabras de Capra:

ningún organismo individual puede existir aisladamente, los animales dependen de la fotosíntesis de las plantas para cubrir sus necesidades energéticas; las plantas dependes del dióxido de carbono producido por los animales, así como el nitrógeno fijado en sus raíces por las bacterias; finalmente, plantas, animales y microorganismos regulan la biosfera y mantienen unas condiciones aptas para la vida. (2003).

Aquí, el autor deja entrever que la organización social tiene un comportamiento natural y que contemporáneamente se observa a través de las redes sociales de comunicación, conocidas hoy como las TIC.

Capra, dentro de su investigación rigurosa y, desde luego, científica, demuestra la existencia de la conectividad entre las ciencias sociales y las ciencias naturales a través del supuesto expuesto, según el cual, no existe organismo alguno aislado al hombre.

Considera que el desarrollo de la vida ha sido a través del desarrollo de las redes químicas, una vez codificada la memoria en macromoléculas, las cuales delimitan las membranas adquiriendo las características esenciales de las células bacterianas actuales.

Considera Capra que la mente y la conciencian supera la división cartesiana entre la mente y la materia, y lo 
confirma diciendo que esta división conceptual entre mente y materia ha dominado la ciencia y la filosofía occidentales durante más de tres siglos, teoría sustentada también por René Descartes. A la vez concluye que la mente y la conciencia no son "sustancias", sino procesos.

Capra hila en su pensamiento muy delgado al tratar la temática o la teoría sobre la cognición, y la aborda a través de Santiago, considerando que consiste en la "identificación de lo cognitivo, o proceso del conocimiento, con el proceso de la vida" (2002). Evidentemente este requisito del conocimiento también lo plantea el psicólogo Piaget, el cual sostiene que para la sumatoria del valor agregado del conocimiento, es necesario un conocimiento previo: por lo tanto, en el estudio de la cognición de los adultos (aprendizaje), está referido sobre todo a la atención, la percepción, el aprendizaje básico y la memoria. También ha contribuido retrospectivamente en esta teoría Sigmund Freud e incluso, Platón.

En otras palabras, dice Capra: "la cognición es el proceso mismo de la vida. La actividad que organiza los sistemas vivos, en todos los niveles de vida, es la actividad mental" (2002). Luego, la cognición es la misma conciencia social por el enlace de la red de conocimientos, y que en un momento dado lo enlaza como la naturaleza de la experiencia consciente a través de los mismos acontecimientos cognitivos.
Capra clasifica la cognición en tres categorías, a saber: 1. La percepción, 2. La emoción y 3. El comportamiento. En esta forma, entonces, no se requiere solamente la existencia de un cerebro y un sistema nervioso, es decir, la ciencia cognitiva está encarnada físicamente en el cuerpo y en el cerebro.

La cognición para Capra, según la teoría de Santiago, está asociada a cualquier nivel de vida, y continua diciendo: "lo que constituye un fenómeno mucho más amplio que la conciencia, es decir que la experiencia vivida conscientemente, se desarrolla a través de un cerebro y un sistema nervioso superior" (Capra, 2002) y emerge cuando la cognición desarrolla un determinado grado de complejidad, el cual es infinito o exponencial.

Vemos como el tema de lo cognitivo es aceptado hoy como un reto en el estudio de la ciencia cognitiva, y se determina sobre sensaciones cualitativas; por tal razón las ciencias sociales como la economía, la política, la antropología y la sociología, deben tener como base de estudio las variables cualitativas, con instrumentos de investigación cualitativos y cuantitativos en cuanto a lo histórico.

Una vez observada la dimensión individual de la consciencia cognitiva, también es importante contemplarla en la dimensión social, a través del sistema de comunicación conocido como el lenguaje simbólico o convencional, sin el cual no podrían entenderse 
las personas. Es a través del lenguaje que se emiten juicios de valor, los cuales tendrán análisis de causas y consecuencias de acuerdo con nuestra cultura, con énfasis en la libertad y en las creencias.

Capra, a manera de resumen, dice: "el mundo interno de nuestra consciencia reflexiva aparece en la evolución de la mano del lenguaje y de la realidad social, lo cual significa que la consciencia humana no es un fenómeno únicamente biológico, sino también social" (2002). Él afirma que la dimensión social de la consciencia reflexiva es a menudo ignorada por científicos y filósofos.

George Lokoff (1971), filósofo americano y fundador de la lingüística cognitiva en los años 70, y Mark Johnson (1989), filósofo estadunidense y científicos de lo cognitivo, realizaron tres descubrimientos capitales: "1) La mente está inherentemente encarnada en el cuerpo. 2) El pensamiento es en su mayor parte inconsciente. 3) Los conceptos abstractos no son en gran medida metafóricos", lo cual obliga a que estas ideas sean aceptadas y se integren en la teoría coherente de la cognición humana. Johnson (2014) y Lokoff (2001) argumentan que la ciencia de la cognición constituye uno de nuestros recursos más profundos para el autoconocimiento: autoaprendizaje autónomo y significativo.

Al tratar de comprender la primera parte del libro de Capra, se encuentra que su objetivo consciente es desarrollar un marco teórico unificado y sistémico para la comprensión de los fenómenos biológicos y sociales. Él considera que las ciencias sociales desde el siglo XIX hasta nuestros días, junto con los principales debates de las escuelas de pensamiento sobre las cuatro perspectivas de la vida social, a saber: forma, materia, proceso y significado, se hallan en contraposición al conocido pensamiento positivista (modernidad y posmodernidad) desarrollado por el sociólogo Augusto Comte (1844), el cual determinó que en las ciencias sociales se deben buscar leyes generales del comportamiento humano, basándose en la cuantificación y en lo objetivo; en otros términos, para él no cuentan las variables cualitativas ni la carga subjetiva por naturaleza, además la fenomenología social como tal, contempla un tiempo y espacio delimitados.

Vemos, entonces, como Isidore Marie Auguste François Xavier Comte (1798-1857), desconocía la posición de Émile Durkheim (1858-1917) y Maximilian Carl Emil Weber (1864-1920), los cuales expusieron que: "los hechos sociales como las creencias o las prácticas eran las causas de los fenómenos sociales".

Estos acontecimientos de descubrimientos científicos desarrollan la dinámica de las culturas y la capacidad de imágenes mentales, que permiten elegir y formular valores y normas sociales de comportamiento; y considero como tales, el aparecimiento en la ciencia política de las constituciones de los Estados, como norma de normas en la convivencia social a través del poder. 
Capra aborda el origen del poder a través del economista John Kenneth Galbraith (1908-2006): "El ejercicio del poder, la sumisión de unos a la voluntad de otros, es inevitable en la sociedad moderna; nada se logra sin él... El poder puede ser socialmente maligno, pero no deja de ser socialmente esencial" (Galbraith, 2013). Al parecer deja vislumbrar la aproximación de la definición de ciencia política, la cual, después de revisar muchos tratados, en resumen es: el estudio del acceso al poder; lo cual permite la resolución de los conflictos originados por el abuso y acumulación del mismo, lográndose así la depuración para la buena forma de la democracia en los Estados.

También se encuentran a partir del siglo $X X$ avances significativos sobre la tecnología, la cual incide en las culturas sociales. El sociólogo Manuel Castells (2012,) la define como: "el conjunto de instrumentos, normas y procedimientos mediante el cual el conocimiento científico es aplicado a una determinada tarea de forma reproducible". Y afirma Capra que la tecnología es mucho más antigua que la misma ciencia; desde luego, porque el hombre inventó para su subsistencia la técnicas de caza y pesca.

En el libro Las conexiones ocultas (2003), segunda parte: Los retos del siglo XXI, se encuentra el aterrizaje del estudio de Capra sobre las organizaciones sociales y los impactos social y material o ambiental y la sostenibilidad del planeta. Considera que en las organizaciones sociales, como en los círculos empresariales y en la administración de empresas, el mundo de los negocios necesita de fundamentales transformaciones. La temática contemporánea es sobre "gestión y cambio", a esto es que apunta la investigación, específicamente sobre lo organizacional y aparece en los nuevos textos de gestión empresarial.

El cambio debe ser paralelo entre lo organizacional y lo tecnológico, porque, hasta nuestros días, esta dinámica ha influido negativamente en el desarrollo y crecimiento económico por la destrucción de medio ambiente y la insostenibilidad del planeta, convirtiéndose la insostenibilidad en la amenaza más grave para la supervivencia de nuestra especie.

Capra, al respecto, considera:

A fin de construir una sociedad sostenible para nuestros hijos, y para las generaciones venideras, será preciso que rediseñemos por completo muchas de nuestras tecnologías e instituciones sociales, así que como que seamos capaces de salvar el abismo actual entre el diseño humano y los sistemas ecológicamente sostenibles de la naturaleza. (2003). 
Se ve que la angustia inicialmente por la vida del planeta y por la supervivencia de nuestras especies, está establecida en nosotros los seres vivos que integramos la Tierra, y como única tarea tenemos la de ponernos a salvar y proteger lo que nos queda del medio ambiente.

Estoy de acuerdo absolutamente con la anterior proposición, porque en verdad las empresas y las organizaciones sociales necesitan de cambios profundos para adaptarse al nuevo entorno global empresarial y buscar su objeto social, que debe ser, llegar a ser ecológicamente sostenible.

Hasta el momento existen organizaciones con propósitos específicos tales como la utilización del poder, la producción de rendimientos para sus accionistas, la transferencia de tecnología y, en algunos casos, incluso la práctica de alguna fe religiosa; pero la fórmula para estos nuevos tiempos está en el ingenio de la mujer y del hombre; y yo diría, en la observación de la naturaleza, en la contemplación de la forma como ella misma corrige sus propios "errores", si es que existen. Pienso que ella simplemente admite los ciclos de reproducción, teniendo en cuenta su adaptabilidad y su diversidad. Por lo tanto, estoy totalmente de acuerdo con la frase de Margaret J. Wheathey (1971): "La vida es la mejor maestra"; además son teorías de la estructura social u organizacional o de ambas.
Por ende, lo cognitivo, que comprende los procesos de aprendizaje significativo, es lo fundamental en la gestión del conocimiento, y el aprendizaje organizativo, tal como lo dice Capra, permite la construcción teórica de importantes conceptos de la nueva teoría en gestión empresarial.

Contemporáneamente, Lewis Henry Morgan (18181881) expone su tesis científica a través de los siguientes cinco aspectos fundamentales:

\section{A las organizaciones como máquinas para el control y la eficacia. 2. A los organismos como desarrollo y adaptación. 3. Al cerebro como aprendizaje organizativo. 4. A la cultura como valores y creencias, y 5 . Al sistema político como conflictos de interés y poder. (Morgan, 1850).}

En resumen, vemos que Morgan asocia los organismos y el cerebro con las dimensiones cognitivas y biológicas, y la cultura y el sistema político con dimensiones sociales. Está claro que, en contraste, aparecen las máquinas, a las que asocia con el control y la eficacia, es decir, se refiere al control del tiempo en la ejecución repetitiva de una tarea, y a la eficacia la relaciona con la fuerza y el volumen productivo (Morgan, 1850). 
En el análisis de la eficacia y el control se ha dejado en la robótica, por muchos aspectos, tales como la carga prestacional en los obreros y sus derechos en la organización sindical, lo cual es previsible en la teoría de rendimientos de acciones para los inversionistas.

Lo más triste de la realidad es que el ingenio creativo del ser humano no lo pueden desarrollar las máquinas porque no tienen sentimientos, no tienen comprensión de los procesos y procedimientos, no tienen innovación, no tienen empoderamiento, no tienen competencias de adaptabilidad a los sistemas sociales, políticos y económicos (sostenibilidad).

Las organizaciones sociales deben replantear la filosofía de las teorías de valores y principios, donde la riqueza no sea la acumulación de bienes para producir escasez y desigualdad social, lo cual contribuye a la falta de oportunidad en la satisfacción de las necesidades esbozadas por Abraham Maslow (2000). El nuevo paradigma es la conservación del planeta para desarrollar dignamente los sistemas de vida que este alimenta.

El énfasis en el poder se ha dado mediante la tecnocracia, y en la administración de empresas a través de modelos lineales precisos, como departamentalización o división del trabajo, especialización o estandarización del mismo, para el crecimiento en la productividad, los fines financieros y los organigramas de mando y comunicación vertical, a lo sumo horizontal, pero en conservación de la líneas de mando; lo cual no deja entrever la humanización que trata exaltadamente Capra en su obra mencionada.

Esta descripción fue esbozada por el ingeniero y economista americano Frederick Winslow Taylor (1856-1915), quien fue considerado como el padre de la teoría de la administración científica, cuya área de estudio fue el nivel operario a través del método y las herramientas para el trabajo. Y por el ingeniero Henri Fayol (18411925) de Estambul, Turquía, quien se dedicó al estudio del área superior de la organización, a través de su filosofía esbozada en la frase: "el arte de gobernar". Fayol también es conocido como el creador de la teoría científica del enfoque clásico de la administración; él dividió el estudio de la administración en catorce grupos, según el grado de importancia, y consideró como primer grupo la división del trabajo, que induce a la especialización y, por lo tanto, promueve la eficiencia.

Para hoy estas teorías están reestructuradas bajo los parámetros de la administración sostenible y el desarrollo económico, versus lo tradicional, donde las variables fundamentales son externas (Drucker, 2012).

Se observa que en la administración tradicional el aporte intelectual a cargo de los directivos y organizadores, y el manejo manual o técnico, quedaron reservados para los empleados u obreros, a costa del desperdicio de los aportes fundamentales de los ejecutores de las tareas 
rutinarias o técnicas, al igual que la posibilidad de la innovación para la competencia en el mercado global.

Precisamente, Capra (2002) al respecto considera: "Los seres vivos, en cambio, actúan de forma autónoma. Nunca podrán ser controlados como las máquinas. Tratar de hacerlo equivale a privarlos de su condición de ser vivos". Con esta afirmación se corrobora que el trato e interpretación de los empleados y obreros debe ser sobre la base de seres vivos humanos. Por ello, como ser vivo implica que es capaz de autorregeneración, de cambio, de adaptabilidad y evolución en forma natural.

Está claro que el actual mundo empresarial, las organizaciones rígidas y mecanicistas, están orientadas a la autoeliminación por sustracción de materia intelectual, es decir ¿cómo puede competir en el actual entorno empresarial global, que es cada día más complejo, orientado a la investigación y rápidamente cambiante? Pues este interrogante permite la reflexión y la necesidad de cambio urgente en la gestión empresarial.

El párrafo inmediatamente anterior nos hace reflexionar sobre las empresas elefante, las cuales son grandes, lentas, tradicionales, de aspecto y estructura fuerte; pero que hoy en el mundo cambiante deben ser las sobrevivientes a través de las políticas de flexibilidad para permanecer en competencia, y a dicha exigencia están llamadas las empresas ratón, rápidas, sagaces y voluntad en número exponencial o varios individuos y adaptabilidad al cambio (Varela, 2001).

Toda esta parafernalia ocasiona la comprensión de la existencia de las redes sociales, sobre lo cual dice Capra (2002):

El análisis de la red social se ha consolidado como un nuevo enfoque de la sociología, y es empleado en la actualidad por muchos científicos para el estudio de las relaciones sociales y de la naturaleza de las comunidades.

También es corroborada dicha tesis por el sociólogo Manuel Castell (2001), cuando afirma que la reciente revolución de la tecnología de la informática ha sentado las bases de una nueva economía, estructurada en redes financieras globales que giran en torno a los flujos de información, poder y acumulamiento de riqueza.

Castell aborda el acuñamiento de una nueva forma de organización humana, Ilamada "sociedad en red", por medio de la cual se ve una nueva estructura social, cuyo componente económico se basa en las transacciones de venta y compra de acciones, convirtiéndose en dinero especulativo, como lo llamó Adam Smith.

El teórico del aprendizaje social en general, Etienne Wenger, denomina comunidades de práctica a las redes sociales autogenéticas (descripción del desarrollo de un órgano), donde a medida que los individuos 
se empeñan a lo largo del tiempo en una empresa común, "van desarrollando una práctica común, es decir formas de hacer las cosas y de relaciones compartidas, que les permiten alcanzar el objetivo común deseado" (Wenger, 2001). Con el paso del tiempo, esta práctica común resultante acaba convirtiéndose en un vínculo reconocible entre los implicados.

Y, naturalmente, las organizaciones sociales en el desarrollo de su quehacer, ya sea en el interior de una fábrica o empresa, o en relaciones extramuros, terminan utilizando las formas más ventajosas y provechosas de sus labores.

Etienne Wenger clasifica en tres aspectos esta experiencia: 1. Implicación mutua de miembros. 2. Empresa común y 3. Repertorio compartido de hábitos, normas tácitas de conducta y conocimiento (con el paso del tiempo). Después, en su marco conceptual, expone que la implicación mutua de miembros se refiere a la dinámica de la red de comunicaciones autogenética; que la empresa común equivale al propósito y al significado común; y que el repertorio compartido de hábitos, corresponde a la coordinación de comportamiento resultante y con el conocimiento compartido (Wenger, 2001).

En síntesis, el sentido de comunidad, más que el sentido de trabajo en equipo, es fundamental para la supervivencia y competencia de las empresas en el siglo $X X I$. Con las anteriores premisas, nace el aprendizaje organizativo, que se ha convertido en el centro de estudio de la teoría de la gestión empresarial, como lo corrobora Margaret Wheathey: "trabajar para una organización que crea intencionalmente conocimiento constituye una excelente motivación, no porque la organización vaya a ser más rentable, sino porque nuestra vida nos parecerá más valiosa" (Wheathey, 1997).

Hasta aquí vemos que la temática ha sido más de atención en la empresa o de análisis en el interior de la misma, aunque, sin duda, tiene un complemento que corresponde al componente exterior, basado en la Organización Mundial del Mercado OMC, la cual es un apéndice de la Organización de las Naciones Unidas ONU, a la que Capra considera como la "Organización de las Redes del Capitalismo Global".

A mediados de los años noventa se creó la OMC teniendo en cuenta la globalización económica, la cual se ha caracterizado por el libre comercio entre las naciones y por la ambición del homus economicus; asunto inicialmente tratado por Adam Smith en su libro segundo de La riqueza de las naciones 1776 (siglo XVIII), y posteriormente por John Stuart Mill (1806-1873) economista inglés (siglo XIX), en su estudio sobre el dinero y la felicidad: "El dinero no se desea para conseguir un fin, sino como parte del fin".

De ser un fin para la felicidad, se ha convertido en el principal ingrediente de alguna concepción indivi- 
dualista de la felicidad. Lo mismo puede decirse de la mayoría de los grandes objetivos de la vida humana -el poder, por ejemplo, o la fama-; "sólo que cada uno de éstos lleva cierta cantidad de placer inmediato, que al menos tiene la apariencia de serle naturalmente inherente; cosa que no puede decirse del dinero" (Alcoberro, s.f.) Luego, el hombre por la búsqueda insaciable del dinero, convencido de que en el encuentra el todo en cuanto a la felicidad, deja por fuera el sentido de la naturaleza en su equilibrio y sabiduría, más otros aspectos intangibles, como la virtud, el reconocimiento y el respeto, a los que no considera vitales como complemento de la felicidad, sino que, en ocasiones, piensa que la fama y el poder es el todo. Además, en semejante búsqueda de riqueza (acumulación de bienes a través del dinero), el hombre ha quebrantado ese equilibrio natural que se conoce como el estudio de la sostenibilidad.

A manera de ejemplo encontramos hoy organizaciones empresariales en el planeta que rompen el equilibrio natural, tal es el caso de las dedicadas a las explotaciones de riquezas del subsuelo como el petróleo, el carbón y el oro, entre otros minerales. La globalización económica en estos aspectos no ha tenido en cuenta el medio ambiente, sino que ha ocasionado la lenta y agónica muerte de los sistemas planetarios.

La creación y propuesta de la OMC, hacia los años noventa, tenía las políticas de expansión económica mundial "globalización de la economía", cuyos beneficios llegarían a todos los países y a cada uno de sus pobladores; pero, hasta el momento, dicho modelo económico ha arrojado un impacto negativo en lo social, político, ecológico y económico, a través de la desintegración social, la quiebra de la democracia, el deterioro más rápido y extenso del medio ambiente, la expansión de nuevas enfermedades, y el aumento en los índices de pobreza y alienación.

Capra y otros científicos ambientalistas han analizado que los propósitos económicos, políticos y sociales son insostenibles por la forma irracional del hombre en la explotación de la naturaleza, estimulado por la ambición del poder económico y político y por la sobreexplotación de los bienes escasos e irrecuperables del sistema de vida del planeta.

Para corroborar el párrafo anterior, basta con observar las crisis económicas de Europa a través de los países como Grecia y España, además de la crisis económica que en la actualidad atraviesa Estados Unidos.

Castells (2001) ha sintetizado el modelo económico de la globalización de la economía, en tres aspectos, a saber: 1. Sus actividades económicas son globales. 2. Su principal fuente de productividad y competitividad es la innovación y 3 . La generación de conocimiento y el procesamiento de información están estructurados con base en redes de información y flujos financieros. En esta 
nueva economía el capital trabaja en tiempo real por la rapidez de la información en las redes financieras, desde ellas se invierte en todos los negocios y actividades económicas, en busca del máximo beneficio económico.

Manuel Castells (2001) llama a estas transacciones financieras, el casino global resultante, y lo clasifica en tres categorías: 1. Opciones de futuro. 2. Fondos de cobertura y 3. Los derivados. La primera son las opciones de compra en un determinado momento, yo diría que es el análisis del coste de oportunidad; la segunda son los fondos de inversión -algunos Estados emiten títulos valor hacia el futuro a través de modelos econométricos o lineales-; y tercero sobre paquetes financieros que pueden ser reales o financieros. Todo este manejo del casino global resultante es sancionado en la filosofía de la ciencia económica de Adam Smith, cuando se refiere a la especulación del dinero por el dinero (1776).

En al impacto social y cultural, nos encontramos nuevamente con Castells (2001) en sus análisis de trilogías.

Fundamentalmente describe como la nueva economía en red ha transformado las relaciones de las fuerzas laborales y el capital:

1. El dinero se ha independizado casi por completo de la producción y de los servicios se ha trasladado a la realidad virtual de las redes electrónicas. 2. El capital se ha hecho global mientras que la mano de obra, por definición, sigue siendo local y 3. Las transacciones son on-line globalmente.

Como consecuencia, capital y mano de obra existen en espacios y tiempos cada vez más distantes: el espacio virtual de los flujos financieros y el espacio real de los lugares locales y regionales donde la gente trabaja; el tiempo instantáneo de las comunicaciones electrónicas y el tiempo biológico de la vida cotidiana.

A manera de ejemplo, encontramos áreas geoeconómicas y geopolíticas del planeta con grandes rasgos fundamentales de atraso en cuanto al término "desarrollo", pues ha aumentado la pobreza, como lo vimos anteriormente, en los países tercermundistas, a los que ManuelCastellsllama"cuartomundo": comprendezonas extensas del planeta que incluyen gran parte del África subsahariana y las regiones rurales empobrecidas de Asia y Latinoamérica, pero se extiende también a partes de cualquier país y cualquier ciudad del mundo.

Sobre el impacto ecológico, dice Castells que el capitalismo global no alivia la pobreza y la exclusión social, sino que, por el contrario, las exacerba. El Consenso de Washington no tuvo en cuenta esos efectos, porque los economistas corporativos excluyen tradicionalmente de sus modelos costes sociales de la actividad económica. Por lo tanto, los modelos econométricos o lineales dejan por fuera el análisis de los costes sociales, costes ambientales y equidad social en términos de 
igualdad de oportunidades, especialmente para los países de las regiones del África y Latinoamérica.

Estas regiones son consideradas como proveedoras de materias primas y mano de obra calificada; caldo de cultivo para la siembra de las maquilas y movimiento de las transnacionales a través de los monopolios y oligopolios; abriendo así cada día más la brecha entre los países industrializados y los proveedores de materias primas.

La nueva economía o globalización ha transformado las relaciones tradicionales de la ostentación y sustentación del poder político; la sociedad en red se ha convertido básicamente en un medio de organización de todos los ámbitos de la sociedad. Castells dice:

El auge de la sociedad en red ha ido de la mano del declive de la Nación-Estado como entidad soberana. Inmersos en redes globales de flujos financieros turbulentos, los gobiernos tienen cada vez menos posibilidades de controlar la política económica de sus países, así como el de cumplir las promesas del Estado de Bienestar tradicional. (2001).

Capra menciona —en cuanto al crecimiento de la corrupción en el interior de la administración pública, y evidentemente en los países de centro-periferia, entendiéndose como centro a los países capitalistas e industrializados y como periferia a los países carentes de los dos aspectos mencionados- el apoyo de los gremios económicos a los agentes políticos porque financian sus campañas electorales a cambio del favorecimiento a sus intereses particulares, los cuales seguramente son internacionales.

La sociedad en red ha ocasionado también transformación en la cultura de los pueblos y las naciones, porque no solamente se trasmiten oportunidades de inversión, sino que también se trasmiten noticias políticas, económicas, de las artes, ciencia y lúdicas. En mi caso, me he visto favorecido por el uso de las TIC en la educación en posgrados virtuales, y exactamente con la experiencia del $\mathrm{PhD}$ o, Doctor of Business Administration (Administración de Empresas) en la Atlantic International University AIU de los Estados Unidos. Pero también grandes segmentos de la población han quedado excluidos de la sociedad en redes, por falta de políticas estatales en inversión de planes, programas y proyectos de informática. Incluso hay países latinoamericanos que todavía no utilizan la red gratis del sistema de comunicaciones llamado software libre, como por ejemplo, Colombia.

El visionario teórico de la comunicación y filósofo canadiense, Marshall McLuhan (1911-1980), citado por Capra (2001), afirmó: "El medio es el mensaje". Se refería exclusivamente a la televisión, que, según él, por causa de su seducción y poder, constituye el medio de comunicación ideal para la "propaganda". 
Tratando de nuevo la temática fundamental de la sostenibilidad, está claro que en los análisis de este ensayo sobre el capitalismo global como único modelo económico en desarrollo, este es insostenible y necesita urgentemente ser rediseñado desde su creación. Amerita esta revisión, porque es absolutamente comprobable su potencial poder de autodestrucción en cuanto al sistema vigente de red en vida.

Cita Capra (2002) a manera de conclusión a Manuel Castells: "El rechazo social, cultural y político, por parte de muchísima gente en todo el mundo, de un autómata cuya lógica o bien ignora o bien devalúa su humanidad". Se refiere a la filosofía o doctrina económica del neoliberalismo en cuanto a la globalización económica, la cual como modelo económico es definitivamente insostenible ecológica y socialmente.

Pienso que la FAO debe comenzar, al igual que los Estados, el cambio de toda esta parafernalia, principalmente hacia los pueblos, lo cual corresponde a una política de seguridad alimentaria, con transferencia de tecnología y con base en lo orgánico, para el desarrollo de la agroindustria, con tierras aptas para los cultivos que den incluso productividad de excedentes, con sustentación de precios y seguro de cosechas para la garantía de la operatividad económica; el desarrollo de una política salarial exclusiva para el trabajador del campo y, por último, la aplicación de una política sobre la injusticia de la tenencia de la tierra, como en el caso colombiano, para no ir tan lejos en busca de un ejemplo.

\section{Conclusiones y recomendaciones}

Considero que debe exhortarse a las ONG, a los gobiernos de los diferentes Estados y a la ONU, para que contribuyan a crear una nueva misión de la visión del hombre sobre la faz del planeta, estableciendo otros objetivos de supervivencia, a través de diferentes metas de enriquecimiento y propósitos de desarrollo personal y colectivo, con valores y principios renovados, fundamentados en el propósito de dejar un legado para nuestros hijos, nietos y futuras generaciones, con la misma oportunidad que hemos tenido todos de encontrar un planeta vivo en red y que se garantice sin egoísmo la supervivencia de la especie humana en el planeta.

El problema, insisto, es de conciencia social, de inteligencia del hombre y de la mujer. Si la vida no es eterna, si tiene un límite, si yo no soy eterno, ¿por qué quiero enriquecerme de forma excesiva? Si al final del camino recorrido por nosotros, somos materia, por favor, jno seamos insensatos!Sobre nuevos valores y principios, o nueva filosofía de la vida, sí podemos aceptar y hablar sobre lo fundamental: la sostenibilidad social, ecológica y económica; debemos ser capaces de implementar planes de acción sobre la igualdad de 
oportunidades y la felicidad de la humanidad, pues, de lo contrario, nos espera la autodestrucción de los sistemas vivos en red, como está ocurriendo.

Vale anotar que este artículo de reflexión se ha desarrollado bajo el género de la escritura argumentativa en la investigación científica, por tal razón, al final de cada tema tratado han aparecido párrafos con conclusiones y síntesis. 


\section{Referencias}

Alcoberro, R. (s.f.). Página web. Recuperado de http://www.alcoberro.info/

Capra, F. (2002). The hidden connections. Nueva York: s.n.

Castell, M. (2001). La ciudad informacional, tecnologías de la información, reestructuración económica y el proceso urbano-regional. Madrid: Alianza.

Comte, A. (1965). Discurso sobre el espíritu positivo. Buenos Aires: Aguilar.

Deleuze, G. (2001). Qué es la filosofía. (6 ed.). Barcelona: Anagrama.

Drucker, P. (2012). Las fronteras de la administración. Inglaterra: Routledge.

Durkheim, E. (1982). Historia del sistema educativo francés. Madrid: La Piqueta.

Galbraith, J. K. (2013). La anatomía del poder. España: Ariel.

Habermas, J. (1998). Facticidad y validez. España: Trotta.

Johnson, M. L. (2014). La moral de los seres humanos: comprensión ética desde la perspectiva de la ciencia cognitiva. Chicago: University of Chicago Press. 
Lokoff, G. (2001). Metáforas de la vida cotidiana. Madrid: Cátedra.

Maslow, A. (1982). La amplitud potencial de la naturaleza humana. México: Trillas.

Morgan, L. H. (1864). Sistemas de consanguinidad y afinidad de la familia humana. México: McGraw-Hill.

Sokal, A. \& Bricmont, J. (1999). Imposturas intelectuales. España: Paidós Ibérica.

Varela, R. (2001). Innovación empresarial. Arte y ciencia en la creación de empresas. (2 ed.). Bogotá: Pearson Educación de Colombia.

Weber, M. K. (1903). La ética protestante y el espíritu del capitalismo. Barcelona: Paidós.

Wenger, E. (2001). Communities of practice, learning, meaning, and identity. New York: Cambridge University Press.

Wheathey, M. (1997). El liderazgo y la nueva ciencia. España: Granica. 